\title{
Pollination Best Practices in Southern Highbush Blueberry in Florida ${ }^{1}$
}

\author{
Rachel E. Mallinger and Douglas A. Phillips²
}

\section{Introduction}

Southern highbush blueberry (SHB) is the primary blueberry species grown in Florida. It is dependent upon pollinating insects for adequate pollination and fruit set (Benjamin and Winfree 2014). Some Florida growers have reported cases of low fruit set in recent years, in particular on the cultivars 'Meadowlark' and 'Emerald', which may have been due in part to poor pollination. In most of these cases, growers observed a heavy bloom followed by poor fruit set, with undeveloped fruit dropping from the plants. Although there may be other causes for this scenario, including heavy flower thrips damage to blossoms, this description is generally indicative of poor pollination. Other symptoms of inadequate pollination include an extended period after flower opening before petal fall, petals turning brown while still on the bush, and a low number of seeds in fruit that does develop. This publication will discuss blueberry pollinators, some causes of poor pollination, and current best practices to reduce the possibility of poor pollination of SHB.

\section{Blueberry Pollinators}

\section{Honey Bees}

The European honey bee, Apis mellifera L. (Figure 1), is the most common pollinator of blueberries in Florida. This bee, as its name suggests, is not native to the United States but rather to Europe and parts of Asia and Africa. In addition to managed colonies, which can be rented during bloom, feral colonies are widespread throughout Florida and can contribute to pollination. However, certain foraging behaviors of honey bees can make them less effective pollinators for blueberries. For instance, workers generally collect nectar but not pollen from blueberry flowers, and will sometimes "rob" nectar through slits in the petals, minimizing contact with the flower's anthers and stigmas required for successful pollination. More visits by nectarrobbing honey bees may thus be necessary to deposit an adequate amount of pollen as compared to other pollinators that make full contact with the flower's reproductive parts. Despite these behaviors, due to their high abundance in blueberry fields, honey bees can significantly increase pollination and fruit set (Sampson et al. 2004).

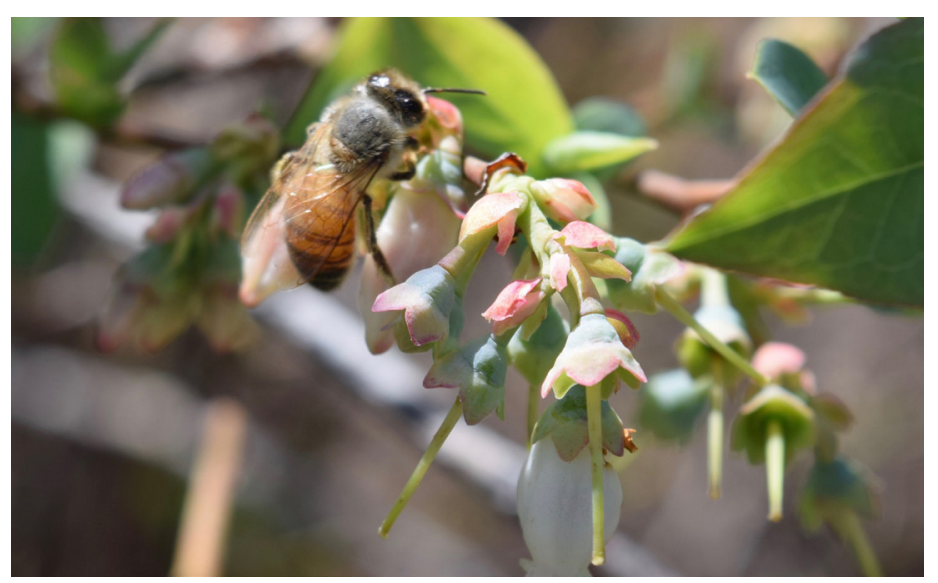

Figure 1. Apis mellifera, the European honey bee.

Credits: R. Mallinger, UF/IFAS

1. This document is ENY-172, one of a series of the Department of Entomology and Nematology, UF/IFAS Extension. Original publication date January 2019. Visit the EDIS website at https://edis.ifas.ufl.edu for the currently supported version of this publication.

2. Rachel E. Mallinger, assistant professor, pollinator ecology and conservation, Department of Entomology and Nematology; and Douglas A. Phillips, blueberry Extension coordinator, Horticultural Sciences Department; UF/IFAS Extension, Gainesville, FL 32611. 


\section{Bumble Bees}

There are five species of social bumble bees (Bombus spp.) native to Florida (Figure 2), all of which can pollinate blueberry flowers. Bumble bees have annual colonies, with new queens initiating colony development and foraging for nectar and pollen in late winter/early spring coinciding with blueberry bloom. Workers are produced by colonies later in the season and are thus less likely to be found on blueberry blossoms. Bumble bees are more efficient pollinators of blueberry flowers than honey bees due to their ability to increase pollen shed through sonication (vibrating the flower by rapid wing movement), a phenomenon called "buzz pollination" (Thorpe 2000). They also actively collect blueberry pollen, deposit more pollen on the blueberry stigma per visit, and visit more flowers per period of time than do honey bees (Strubbs and Drummond 2001). Studies have shown that four visits by a honey bee are required to deposit the same amount of pollen as a queen bumble bee, and bumble bees can pollinate up to 6 flowers in the time it takes honey bees to pollinate one flower (Javorek et al. 2002). In addition, bumble bees are more active than honey bees during poor weather conditions (Tuell and Isaacs 2010).

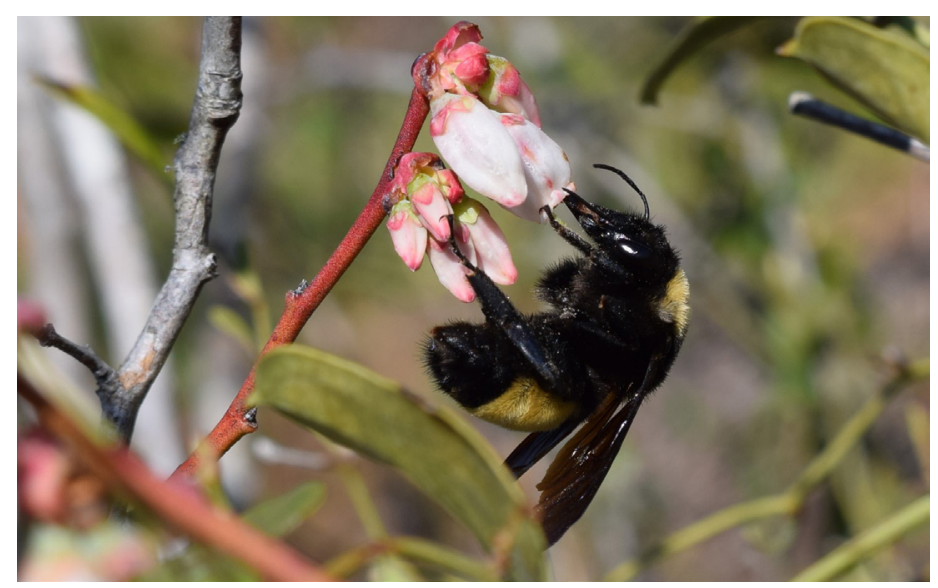

Figure 2. Bombus pensylvanicus, the American bumble bee. Credits: R. Mallinger, UF/IFAS

\section{Southeastern Blueberry Bee}

Florida is home to a native specialist of blueberries, the southeastern blueberry bee Habropoda laboriosa (Figure 3). This species is solitary (with no division of reproduction or labor) and resembles a small bumble bee. Female bees build their nests below ground in sandy soil, often nesting communally in large aggregations. As a specialist bee, the southeastern blueberry bee is dependent on, and highly attracted to, blueberries. Like bumble bees, they are very good pollinators for blueberries, facilitating pollen shed through sonication or buzz pollination (Sampson et al. 2004). In addition, these bees are less likely to visit alternative flowers in the region compared to other bees, often foraging exclusively on blueberries. However, these bees emerge close to the bloom time for wild blueberries, which is towards the end of SHB bloom, and thus too few individuals may be present to adequately pollinate early-blooming cultivars without the help of other managed pollinators.

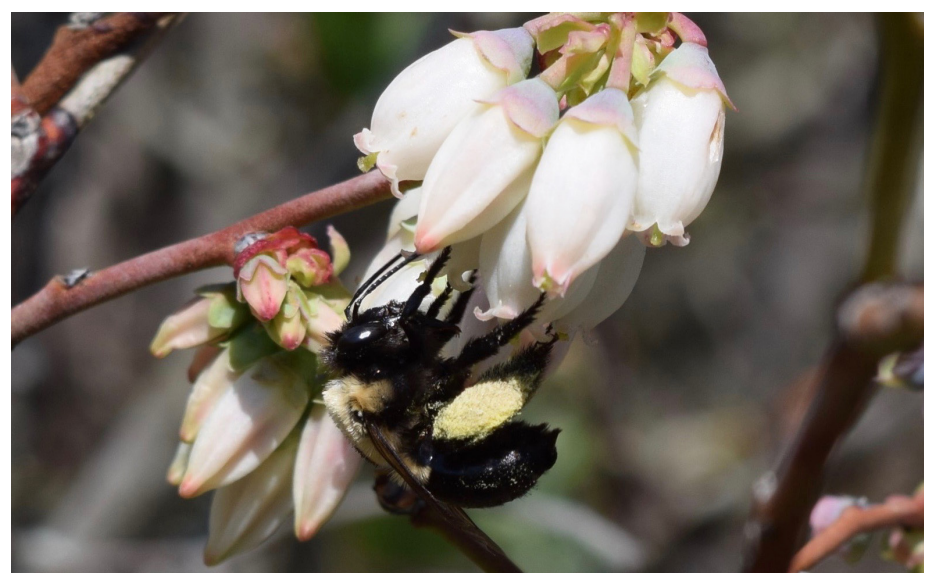

Figure 3. Habropoda laboriosa, the southeastern blueberry bee. Credits: R. Mallinger, UF/IFAS

\section{Carpenter Bees}

There are two species of large carpenter bees in Florida, Xylocopa virginica (black with yellow hairs) (Figure 4) and Xylocopa micans (all black or dark blue), both of which can be found on blueberry blossoms. These carpenter bees also resemble bumble bees but can be distinguished from them by their shiny, relatively hairless abdomens. They are solitary and nest above ground in wood tunnels that they excavate. Unlike bumble bees or the southeastern blueberry bee, carpenter bees are not particularly good pollinators for blueberries. Carpenter bees, like honey bees, rob nectar from blueberries by creating a slit in the petals, thereby avoiding contact with the flower's reproductive parts. However, studies have found that this behavior can still pollinate blueberry flowers (although to a lesser degree) (Sampson et al. 2004). Furthermore, these slits could encourage subsequent visits by honey bees, which additionally contribute to pollination, although again, to a lesser degree (Sampson et al. 2004).

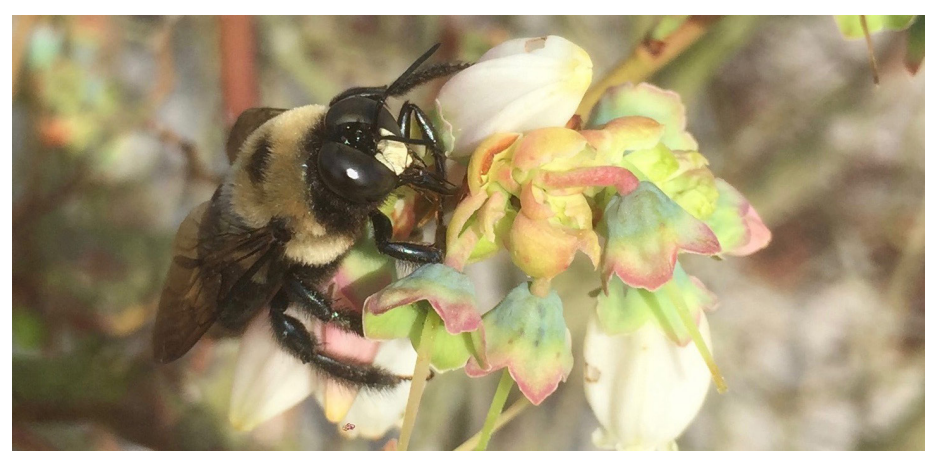

Figure 4. Xylocopa virginica, the eastern carpenter bee. Credits: R. Mallinger, UF/IFAS 


\section{Other Native Wild Bees}

Other bees also pollinate blueberries, including sweat bees (Halictidae) and mining bees (Andrena spp.). However, due to the early bloom time of SHB in Florida, they are generally not very abundant or frequent. These bees vary in appearance from metallic green to black and white striped to all black and are primarily solitary, ground-nesting species.

\section{Issues That Can Lead to Poor Pollination}

\section{Self-Incompatibility and Single-Cultivar Plantings}

Although SHB are capable of producing fruit when selfpollinated (i.e., when pollen from one variety is transferred to a flower of the same variety), various studies have found that cross-pollination with a different variety can result in greater fruit set, larger fruit, and earlier fruit maturity (Taber and Olmstead 2016). One explanation for this is that cross-pollination increases the number of viable seeds in the fruit. Some growers have planted single SHB cultivars in large solid blocks, since these can be easier to manage. These types of plantings will set fruit, but, depending on the cultivar, most varieties will not perform up to their full potential due to a lack of cross-pollination.

\section{Too Few Bees}

Bees and other pollinators are needed to release blueberry pollen and to move pollen across flowers, including between flowers on the same bush and bushes of the same variety (self-pollination), or across different varieties (cross-pollination). Without pollinators, flowers may shed some pollen on their own and self-pollinate, but yields will be lower and more variable. General recommendations are 4-8 honey bees foraging per blueberry bush in peak bloom and during the warmest part of the day; fewer numbers of honey bees may result in a pollination deficit. But if more effective pollinators, such as bumble bees, are present, fewer individuals may be needed for adequate pollination. Having too few pollinators can be a problem if growers do not rent the recommended numbers of managed bees, if colonies are smaller than typical, or if wild bees are sparse.

\section{Inefficient Bee Foraging Behaviors}

Even with the recommended number of bees, pollination problems can occur if bees do not effectively pollinate blueberry flowers. Ineffective pollination can occur under two general scenarios: 1) bees that are present on the farm or in the area are not visiting blueberry flowers, or 2) bees are visiting blueberry flowers but not effectively causing pollen release or depositing pollen. Under the first scenario, bees may not forage on blueberries if there are alternative, more attractive floral resources in the region. Large-bodied social bees, including honey bees and bumble bees, can forage over a mile from the colony and will visit a variety of plants. Under the second scenario, certain bees, including honey bees and carpenter bees, may frequently visit blueberry flowers, but because they do not buzz pollinate, they are not as effective in stimulating pollen release. Furthermore, they frequently "rob" nectar from the flower without depositing large quantities of pollen. Visits by inefficient pollinators can still contribute to pollination, but a greater number of visits is required to achieve high fruit set and quality. Therefore, a greater number of ineffective pollinators is required to obtain the same yields as a smaller number of effective pollinators.

\section{Wet or Windy Weather}

Poor weather conditions can interact with plants and pollinators to cause pollination problems. In cloudy, cool, or rainy weather, bees may not forage. This is especially true for honey bees, while bumble bees are more active under cool conditions. Additionally, under high humidity flowers may not shed pollen as readily, making them more dependent on buzz pollination for pollen release (Lyrene and Williamson 2003). Under these high-humidity conditions, buzz pollinators, including bumble bees and the southeastern blueberry bee, may be especially necessary to stimulate pollen release.

\section{Large Farm Size}

Farms of only a few acres may have fewer pollination problems, especially if they are surrounded by forest land where wild bees may be more abundant and diverse. As farm size increases, achieving adequate pollination may become more difficult due to a combination of fewer pollinators per flower and cultivar planting arrangements that limit cross-pollination.

\section{Flower Thrips}

If thrips are numerous during bloom, they can reduce or eliminate pollination. Damage by thrips significantly reduces the number of hours during which flowers are receptive to pollen. With heavy infestations, thrips may destroy the flower reproductive organs, making pollination impossible. 


\section{Practices for Increasing Pollination Effectiveness}

\section{Mixed-Cultivar Plantings}

Current recommendations are to interplant at least two unrelated cultivars sharing a similar bloom period within the same general area. Although there is no specific guidance on the ideal number of alternating SHB rows, planting large solid blocks of single cultivars is not recommended. Guidance from Michigan State University on the optimum planting for northern highbush blueberry recommends alternating blocks of up to eight rows per cultivar for sufficient cross-pollination (Isaacs et al. 2016).

\section{Pollinator Density}

There must be sufficient pollinators in the field to achieve good pollination. Current recommendations for the number of honey bee hives per acre range from 3 to 5 for a standard density planting (approximately 1,700 plants per acre). The recommendations will increase for high-density plantings. In addition, if the weather is very warm and causes a more concentrated bloom or if it is cold, cloudy, or windy and not conducive to honey bee activity, or if there are other flowering crops or wild plants blooming at the same time as SHB, a greater number of bees may be required for sufficient pollination. Alternatively, if there are significant numbers of wild pollinators in the field, including bumble bees or the southeastern blueberry bee, fewer honey bee colonies may be needed. All of these factors should be considered when determining the number of honey bee hives required.

\section{Honey Bee Hive Placement Timing}

Bee hives should be placed in the production field ideally at or after $10 \%$ bloom but before $20 \%$ bloom. If the hives are placed in the field too early, the bees may begin to forage outside of the area, resulting in insufficient bee activity on the blueberry plants during bloom. Blueberry flowers are typically only receptive to pollen for 3 to 5 days following bloom opening, so it is important to have sufficient bees in the field during this short period.

\section{Honey Bee Hive Placement Location}

Bee hives ideally should be spread out across the farm (with a maximum of 300 yards between hives) as close to the blueberry plants as possible without obstructing normal production operations and as far away as possible from any other crops or wild plants that are blooming during the same time. However, this distribution may not be possible due to the management requirements of the colonies because beekeepers may want convenient access to the colonies throughout bloom. In this case, hives should be distributed to the extent possible. The hives should be oriented east or southeast so that they are exposed to early morning sun, and also sheltered from strong winds.

\section{Checking Honey Bee Colony Health}

It is important to check the health of bee colonies upon delivery and throughout the bloom period. Of the typical ten frames in a honey bee hive, eight or more should have adults covering the frame, and six or more should have brood in the cells of the frame (Figure 5). The colonies should remain active during good weather, with steady flight into and out of the hive and bees active on the blueberry flowers. The grower may want to consider entering into a pollination contract with the beekeeper to define expectations and responsibilities (sample contract at http:// edis.ifas.ufl.edu/aa169).

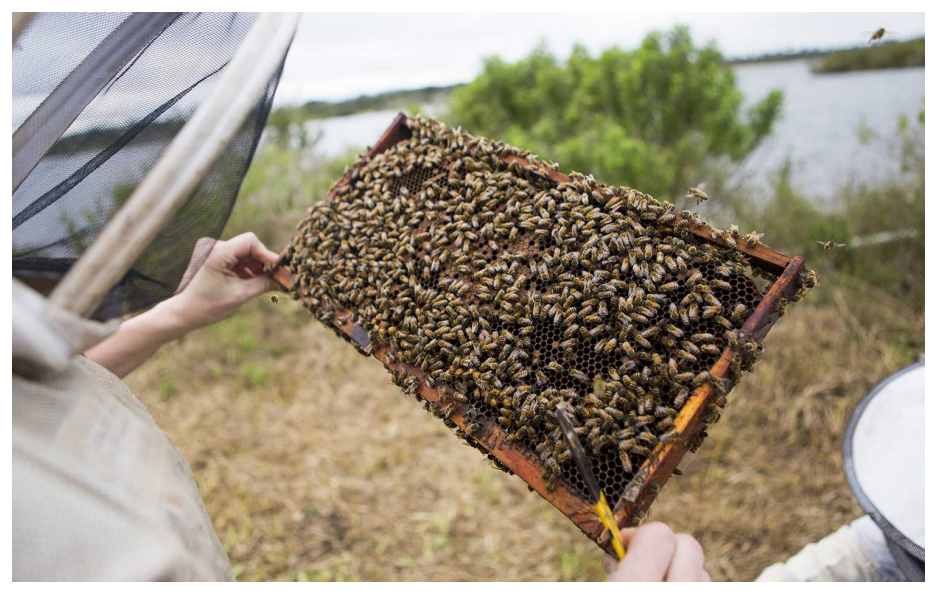

Figure 5. Honey bees on hive frame.

Credits: UF/IFAS

\section{Managed Bumble Bees}

Given the greater pollination efficiency of bumble bees, growers should consider adding managed bumble bee colonies to supplement honey bees for successful pollination. Bumble bee colonies are typically purchased in packs of four, called a "quad" (Koppert Biological Systems, Howell, MI), and used at a recommended density of 1 quad per acre (Drummond 2012), supplemented with honey bees. Many of the recommendations for the placement, timing, and colony health of honey bees also apply to managed bumble bee colonies. Bumble bee colonies should be distributed throughout the farm, placed in the field between 10\%-20\% bloom with the entrance door facing east or south east, and sheltered from wind. Additionally, place bumble bee colonies at least 25 feet from honey bee colonies. Each colony should come with approximately 125 adult workers (500 total per quad), and these bees should be observed entering and exiting the colony on warm, dry 
days (observations should be made over a one-hour period due to smaller colonies and long foraging periods). Bumble bee colonies, unlike honey bee colonies, are annual (not living more than one year) and will thus need to be purchased new each season.

\section{Increasing Wild Pollinators}

Native wild pollinators, including wild bumble bees and the southeastern blueberry bee, can be more efficient pollinators of blueberry than honey bees. In order to attract and provide habitat for these wild bees, growers may consider planting wildflowers or flowering shrubs and trees along the edges of the farm, making sure to use plants that do not bloom at the same time as blueberries. While recent research in Florida did not find that such wildflower plantings increased blueberry yields, wildflower plantings have increased yields in other blueberry-producing regions (e.g., Michigan) (Blauuw and Isaacs 2014). It is important to include plants that will flower throughout the period that wild bees are typically active. For the southeastern blueberry bee, which has a relatively short foraging period, from February to April, this means including flowers that bloom in late winter and early spring. Alternatively, bumble bees are active for much of the year in Florida, from February to November, and require flowers throughout that entire period. For southeastern blueberry bees, lateblooming blueberry cultivars may be particularly effective at providing floral resources. For bumble bees, attractive plants that bloom during late spring through fall include bee balm, salvia, mint, sunflowers, blanketflower, tickseed, thistles, and blazing star.

\section{Careful Pesticide Use}

The best time to spray pesticides during bloom is late evening, when bees are not foraging and the residue has time to dry before any bee activity begins the following morning. Pesticide selection is also important in protecting bees. Delegate ${ }^{\circledast}$ WG (Spinetoram) and Entrust ${ }^{\circledast}$ (Spinosad) are toxic to bees for 3 hours after application (until it has thoroughly dried) but are relatively nontoxic to bees thereafter. Neonicotinoid insecticides should be avoided during or shortly before bloom.

\section{Selected References}

Benjamin, F., and R. Winfree. 2014. "Lack of pollinators limits fruit production in commercial blueberry (Vaccinium corymbosum)." Environmental Entomology 43(6):1574-1583.
Blaauw, B. R., and R. Isaacs. 2014. "Flower plantings increase wild bee abundance and the pollination services provided to a pollination-dependent crop." Journal of Applied Ecology 51: 890-898.

Drummond, F. 2012. "Commercial bumble bee pollination of lowbush blueberry." International Journal of Fruit Science 12: 54-64.

Isaacs, R., J. Gibbs, E. May, E. Hanson, and J. Hancock. 2016. "Invest in pollination for success with highbush blueberries." Michigan State University Extension.

Javorek, S. K., K. E. Mackenzie, and S. P. V. Kloet. 2002. "Comparative pollination effectiveness among bees (Hymenoptera: Apoidea) on lowbush blueberry (Ericaceae: Vaccinium angustifolium)." Ann Entomol Soc Am 95: 345-351.

Lyrene, P., and J. Williamson. 2003. "Blueberry fruit set as related to relative humidity in north central Florida in spring 2003.” Proc. Fla. State Hort. Soc. 116: 21-25.

Sampson, B. J., R. G. Danka, and S. J. Stringer. 2004. "Nectar robbery by bees Xylocopa virginica and Apis mellifera contributes to the pollination of rabbiteye blueberry." Journal of Economic Entomology 97: 735-740

Stubbs, C. S., and F. A. Drummond. 2001. "Bombus impatiens (Hymenoptera: Apidae): an alternative to Apis mellifera (Hymenoptera: Apidae) for lowbush blueberry pollination." Journal of Economic Entomology 94: 609-616

Taber, S. K., and J. W. Olmstead. 2016. "Impact of crossand self-pollination on fruit set, fruit size, seed number, and harvest timing among 13 southern highbush blueberry cultivars." HortTechnology 26(2): 213-219.

Thorp, R. W. 2000. "The collection of pollen by bees." in: Dafni, A., M. Hesse, and E. Pacini, (Eds.), Pollen and Pollination. Springer Vienna, Vienna, pp. 211-223.

Tuell, J., and R. Isaacs. 2010. "Weather during bloom affects pollination and yield of highbush blueberry." Journal of Economic Entomology 103(3):557-562.

\section{Additional Resource}

Isaacs, R., N. Williams, J. Ellis, T. Pitts-Singer, R. Bommarco, and M. Vaughan. 2017. "Integrated crop pollination: combining strategies to ensure stable and sustainable yields of pollination-dependent crops." Basic and Applied Ecology 22: 44-60. 